\title{
An Evening at the Ballroom: Whatever Happened to Televanilla?
}

\author{
Wolfgang Muench \\ LASALLE College of the Arts \\ 1 NcNally Street, 187940 Singapore \\ wolfgang.muench@lasalle.edu.sg
}

\begin{abstract}
This article re-introduces the submerged 1968 performance Televanilla, an improvisational theatre dance piece that deployed analogue image-processing tools to establish a dialogical system with technological media. It argues that the performance anticipated principal concepts and strategies for real-time human-machine interaction, and the "virtual" representation of participants in mediated art environments. Although the performance received reviews from renowned critics in prominent New York newspapers and magazines, it disappeared from the historical records almost entirely. The article provides a critical evaluation of the artists' conceptual and technical approaches towards the deployment of analogue media technology for creating an early example of audience participation and human-machine interaction in mediated artworks. This analysis is complemented by an evaluation of contemporary reviews of the performance to illustrate to what degree the critical reception at the time was prepared to appraise the concept of technology-based interactivity through a human-machine interface in artworks appropriately.
\end{abstract}

Media Art History, Image-Processing, Audience Participation, Human Machine Interaction, Interactive Art, Dance Performance

\section{INTRODUCTION}

The submerged 1968 performance Televanilla presents a fascinating example for the transformation of the concept of audience participation in performance art into the notion of a technology-based human-machine interaction with an electronic device. It provides a reference point for the discussion of the developments in analogue media technology in the 1960s and their relevance as a medium for artistic expression in the New York media-technological avantgarde art scene. It reemphasises that the conceptual roots for interactive human-machine interfaces trace back to performance art practices in that time. Furthermore, it exemplifies numerous artistic activities at the crossroads of various cultural, artistic and technological developments that fostered the emergence of concepts of human-computer interactivity in Interactive Media Art.

\section{OVERVIEW}

On 22nd of April 1968, the Martinique Theatre in New York opened its doors for Televanilla, a onenight event introduced in the evening's program as an "improvisational theatre dance piece". The conceptual trajectory was an extensive deployment of television technology in an attempt to "explore new dimensions in the dance experience" in an "evening of experimental interaction between audience, performer and simultaneous T.V. system", as stated in the press release for the event (Boutourline, 1968).

The performance involved five artists, one assistant, one film projector, seven video monitors, one television camera, two custom-built electronic special effects devices, a three-sided thrust stage, and an audience of about 200. However, it disappeared from the historical records for the best part of half a century shortly after its debut. There is hardly any material that referenced the event, and the only visual material left from the performance is a blurry photography that remained in the possession of Susan Buirge, one of the artists involved.

As part of the overall artistic concept, and as a tribute to the available technology, the stage design was kept entirely in black and white. The audience could opt for a colour viewing of the stage and the television monitors by using one of the three chromatic gels included in a sealed packet together with the program and the press release. Most notable from the spectator's point of view was probably how the performance incorporated the technological devices into the scenographical approach. Media technology was openly featured on 
stage to such a degree that The New York Times in its next day's review observed that the dancer was "assisted" on stage by a "battery of technology" (Maskey, 1968). The candid deployment and display of television equipment and 500 meters of cables on stage, in conjunction with the event's vanilla ice cream extravaganza during the first interval, gave the whole evening event the charming, if slightly mysterious title: Tele \& Vanilla. ${ }^{1}$

Televanilla must have been a surprising prospect for an audience which had come to see a dance performance. From a technological point of view, it certainly was quite remarkable. By the end of the 1960s, the use of pre-recorded media material, custom-prepared slide photography, and film footage projected onto actors and stage was a relatively established feature in the New York performance art scene, closely related to the works of Alwin Nikolais and Merce Cunningham, although far from being widely adopted. The deployment of electronic television technology for a small-scale experimental dance performance presented a rather unusual approach at the time. However, putting a whole set of television and broadcast technology, comprising of cameras, monitors, cables, and equipment of all sorts on and around a stage was, even against the backdrop of the late 1960s New York avant-garde performing art scene, a rather unique and quite daring undertaking.

\section{ARTISTS}

Directly involved in the performance were five artists. Their diverse biographical backgrounds and expertise are a testimony to this peculiar 1960s' mélange that fostered the conception of such a technical environment in an artistic context.

Serge Boutourline, Harvard School of Business Administration graduate, inventor, communication theoretician, environmental psychologist, and founder of Interaction S ignal, I nc, a New York registered company concerned with the design of responsive environments and computer controlled interactive devices. Boutourline was instrumental for the organizational aspects of Televanilla. He collaborated with Buirge on the third section with Videosketch.

Susan Buirge, a University of Minnesota graduate, with one year of postgraduate studies at Juilliard School of Music, dancer and choreographer. Buirge conceived and designed the overall artistic concept of the event together with Boutourline. She was the sole dancer-performer of the evening and developed the choreography for all sections, particularly the deployment of various television technologies in the context of a dance performance. She launched her career in New York in 1963 as a dancer with Alwin Nikolais, a key figure in American modern dance renowned for his modernist approach to dance performance, and the inclusion of sound, light and image technology on stage.

Wynn Chamberlain, a pioneer realist painter, filmmaker and novelist. In the second half of the 1960s, he increasingly shifted focus from painting to the New York underground movement in theatre and film and became involved in Andy Warhol's Factory circle. Chamberlain conceived of the second section, Extension No 1, in collaboration with Buirge.

Philip Glass, American composer of music with repetitive structures. Although Glass was present at the event, his involvement was only marginal. He gave his permission to use a tape recording of one of his unpublished compositions for the third section.

Eric Siegel, a self-taught expert in state-of-the-art television electronics, and at the time described as a technological whiz kid. In 1967, Siegel started to build electronic image processing devices that soon attracted the attention of the emerging television art scene in New York. Siegel, who was assisted by Peter Sorensen, ${ }^{2}$ collaborated with Buirge on the conception and realisation of the first section, Flavors. This collaboration was particularly concerned with the incorporation of the 'Magic Box', one of Siegel's early custom-built electronic devices for video image manipulation and processing.

\section{TECHNO-CHOREOGRAPHY}

Televanilla consisted of three distinct sections, each between 12 to 15 minutes in duration that were separated by two intervals. During the first interval, the artists offered the audience vanilla ice cream. The second interval provided them with the opportunity to leave comments on bulletin boards placed on the stage. After the end of the last section, the audience could play around with the technical gadgets used during the performance.

In the first section, Flavors, the television camera, mounted on a large professional studio tripod dolly, and its operator took centre stage. The dancer quite literally revolved around them to the sound of a popular music piece. The camera, operated by Siegel, closely followed the dancer's path on stage and captured her with frequent zooms from full-body shots to focusing on her upper torso and face. The live-recorded television signal of the dancer was channelled through an electronic image-processing tool. This device allowed for the manipulating of the image by applying various degrees of electronically generated solarisation and oscillation effects, either manually or automatically through the audio input channel. The technical process happened in real time with virtually no noticeable delay (Siegel, 1992a). The image-processed signal was then simultaneously displayed on the seven television monitors placed at the fringes of the stage, facing the audience. The visual output of this device was 
an abstraction of the video footage, with patterns of black lines surrounding and radiating from the shape of the dancer's body.

The piece constituted an intimate relationship between the dancer and the camera, and alluded to the concept of a pas de deux in classical ballet, although with one dancer replaced by a camera. In this technical set-up, the dancer could not see the visual output on the monitors. The audience, however, was afforded two opportunities to watch the performance: Either to view the reality on stage, or to perceive the performance in the form of the abstracted representation of the dancer in a mediated space through the perspective of the camera operator.

In Extensions No. 1, the second section, the dancer followed the choreography of a pre-defined path across the entire stage. The television camera was located stationary at the far end of the stage, and the seven monitors displayed simultaneously the realtime transmitted camera image of the dancer's face. Pre-recorded film footage of the dancer's legs and feet in movements similar to the live performance was projected on a vertical screen located upstage, and the dancer attempted to keep her movements in close sync with the projected material. ${ }^{3}$

The development of the choreography for the piece was concerned with the particular spatial dimensions of the theatre and accompanied by a soundscape produced by the dancer from audio recordings in natural environments. Conceptually, the piece investigated notions of space and time on several levels. The dancer's presence constituted itself in real space on the stage, as well as in the mediated space of two different media: the real-time television imagery on the monitors and the prerecorded synchronised film material on the screen. Furthermore, the dancer's full body on stage was juxtaposed with partial views of her body displayed through television and film technology.

The various elements of this mediated reality across space and time assumed equal prominence in the scenography of the performance, and the audience was invited to consolidate their personal perception at the individual level through the process of reassembling the disjointed fragments of the dance. With its particular use of mediated representation of reality, Extensions $N$ o. 1 was the section of the evening that displayed the closest references to artistic concepts of more established avant-garde dance theatre at the time, for example, the performances of the Nikolais Dance Company.

Videosketch, the final part, presented the most radical departure from established dance theatre practices. The dancer performed with five small light bulbs attached to hands, ankles and head about two to three meters in front of a piece of hardware that lent its name to the whole section. Videosketch was a cabinet sized black console located upstage with a TV monitor on top, and a television camera placed at a height of about one meter facing the dancer. The live camera signal was electronically manipulated to display trails of the lights' movement within the camera's field-of-view on the monitor. The technical device provided real-time control of a range of variations of these white calligraphic designs in size, pattern, and luminosity, as well as the length of time before these light trails faded out. The light bulbs on the dancer were connected through cables to the main light board, which allowed full control of their brightness level at any point in time.

The Videosketch section introduced a playful interrelation between reality and mediated representation. The brightness levels of stage lights and the light bulbs attached to the dancer were anticyclically increased and decreased. When the stage lights were fading out, the lights on the dancer got brighter, and vice versa. It resulted in a transition from the visible reality of the dancer on stage into two distinct notions of mediated representation of the dancer when the stage lights were turned down. Firstly, the dancer's presence was manifested through the visible glowing light bulbs that moved in the darkness of the stage, and secondly through the image-processed television signal as displayed on the monitor. The choreography for the piece emphasised the creation of geometrical figures in dance and the representation of the dancer's movements on the television screen constituted a mediated abstraction of her dance in real-time.

The resulting visual output alluded to the process of sketching with lights on the canvas of an electronic video monitor, thus the title Videosketch for the device. At the end of the piece, the audience was invited to perform light-sketching experiments with the apparatus.

\section{HUMAN-MACHINE INTERACTION}

Televanilla incorporated two distinct technological approaches. Firstly, the artists used a closed-circuit television system in all three sections, in which a television camera transmits the electronic signal to one or more directly connected television monitors in real-time. Secondly, for two of the three parts, the artists integrated custom-built special effects devices into the closed-circuit television system between camera and monitors. This incorporation of custom-built image-processing devices presented cutting edge technology to the dance theatre in April 1968.

Moreover, the conceptual novelty realised in Televanilla was to put a human performer inside the input and output components of the closed-circuit television system installed on stage and to combine this system with an image-processing device that 
generated an aesthetically manipulated visual output in real-time on the monitors. Kwastek argued in 2013 that closed-circuit video installations do not "enable technological interactions" since they do not provide "positive reaction by the technical system to input" (Kwastek, 2013).

However, the system deployed in Televanilla provided such immediate feedback to kinesthetic actions of the participants detected by the camera input. It converted the techno-artistic environment into a cybernetic system in which both user and technological components assumed equal importance for the gestalt manifestation of the artwork through an interdependent process facilitated by human-machine interaction.

This 'virtual' representation of the dancer assumed independence from its source in reality. Televanilla explicitly denied any attempt at presenting reality asis in the multiple electronic instances of the dancer on the monitors. Instead, the performance created the framework for an electronic 'virtual' representation of the dancer using the distinct visual aesthetics that the deployed technical system could generate. The particular relationship between the dancer and the electronic visualisation in the technical system remained easily recognisable for the audience, as the system corresponded directly and in real-time to her behaviour on stage.

It also introduced a unique visual language and grammar for this mediated representation. Contemporary reviews described the aesthetic qualities of this visual language in the first section as "ghostly traces" (Siegel, 1968) with "flame running around [the dancer] and streaming off her fingertips" (Jowitt, 1968). In the final section, the reviews spoke of "green blobs, squiggles, fat and thin lines" (Jowitt, 1968) that were received by the device's "electronic eye or radar" (Siegel, 1968) in the final section.

\section{TECHNO-ARTISTIC CONTEXT}

Two art events in the late 1960s, Billy Klüver's ground-breaking 9 Evenings about one and a half years earlier, and Howard Wise's seminal show TV as a $C$ reative $M$ edium roughly one year later, present a contextualising artistic and technological framework for Televanilla related to the incorporation of techno-artistic concepts for audience participation and interaction in video artworks and performances.

For these two events, the participating artists deployed similar technical solutions, although there are distinct differences observable. In 9 Evenings, Robert Whitman's Two Holes of $W$ ater, Öyvind Fahlström's Kisses $S$ weeter than Wine, and Alex Hay's Grass F ield created a multi-screen media scenography through projections of either prerecorded videos, live television broadcast, or video signals captured through CCTV systems. None of these works however incorporated imageprocessing devices for any manipulation of the video signal before it was projected back onto the screen.

Lucinda Childs' Vehicle and David Tutor's Bandoneon used audio-visual or kinetic events as input for electronic signal-processing devices, but neither Childs nor Tutor used these tools for a direct manipulation of live camera feeds.

John Cage's Variations VII used photoelectric sensors to capture movements on stage that triggered playback of pre-recorded video material on stage. There was, however, no direct interrelation between the flow of the performers on stage and the projected visual material from VanDerBeek and Paik (EAl Archive, 2014).

In the 1969 TV as a Creative Medium, Nam June Paik and Charlotte Moorman's TV B ra for Li ving Sculpture, Joe Weintraub's ACTV, Thomas Tadlock's Archetron, Aldo Tambellini's Black Spiral, and Eric Siegel's Psychedelevision $i$ n olor presented either pre-recorded or real-time manipulations of audio-visual material. The artists deployed image-processing devices to perform these manipulations in response to signals received from internal or external sources. None of these various approaches, however, applied imageprocessing equipment to manipulate a live transmitted video image received through a CCTV system.

Earl Reiback's Three Experiments within the $T V$ Tube, Paul Ryan's Everyman's Moebius Strip, Serge Boutourline's Telediscretion, Paik's Participation TV, Frank Gillette and Ira Schneider's collaborative work Wipe Cycle incorporated direct human-machine interaction through customised human-machine interfaces, often in conjunction with CCTV systems. These artworks, particularly those of Paik, Gillette and Schneider, presented sophisticated approaches to audience participation, as well as interesting examples of innovative interfaces between participants and technology. However, none of these works introduced the combination of a camera-based human-machine interface with an image-processing device for defining a mediated environment proper to establish a conceptual dissociation between reality and its electronic representation.

Thus, it appears that none of the performances and artworks presented in $9 E$ venings or $T V$ as a Creative Medium pursued the particular conceptual approach that Televanilla introduced in two of the three sections. Furthermore, Televanilla provided agency for the user to interactively control, albeit only to a limited degree, the electronic representation in an alternate version of reality on the display monitors. 


\section{PIONEERING CONCEPTS}

Neither the still accessible historical records nor critical reviews of early Video Art and Interactive Art written in the decades since then make a reference to a similar approach to the deployment of television technology as part of a dance performance so early in the 1960s. It is therefore not too far-fetched to consider Televanilla as one of the first events that included real-time television technology in a dance performance, as Susan Buirge claims in her 2012 autobiography (Buirge, 2012).

More importantly, however, it suggests that Televanilla was a pioneering dance performance that presented a sophisticated conceptual framework and technical system for an artistic environment with media technology. It facilitated communicative feedback processes between the performer and her visual representation in virtual space and introduced a human-machine interface based on movements, gestures, and the non-verbal 'language' of dance in real space.

Of course, in the absence of a digital computer for an evaluation of the input signal, there was no substantial reconfiguration of the system based on algorithms and logic procedures. The capabilities of the image-processing device were considerably limited and in no way comparable to the audio-visual responses and processes that a digital generalpurpose computer can generate. In essence, however, it constituted an analogue computer built for the very distinct purpose of manipulating certain visual attributes and qualities of the electronic image signal. ${ }^{4}$ The resemblance of the underlying technoartistic concept to works that were created more than a quarter of a century later under the label 'Interactive Art' is nonetheless striking.

\section{VIRTUAL REPRESENTATION}

It would take around five years more before Myron Krueger presented Videoplace, a pivotal artwork in the history of interactive art that deployed a closedcircuit camera system combined with a digital computer system. Some of the visual effects that the digital graphic computer in Videoplace could generate displayed quite a similar aesthetic approach to that produced by Televanilla's analogue machines. Obviously, there can be no doubt that Krueger's digital environment was by far more powerful than Televanilla's analogue technology and provided opportunities for human-machine interaction that the performance could not achieve.

However, Krueger's basic definition for such responsive environments, which he published in 1977, carries a substantial conceptual overlap with the approach that the artists in Televanilla introduced. Krueger described such environments as a "new art medium" that provides real-time human-machine interaction through a system comprising of sensing, display and control components. The system would process the input gathered from the environment into an aesthetic output that the participants could easily recognise as corresponding to their behaviour, actions, and movements. In a 1977 article, he coined the term 'artificial reality' for this kind of technical environment (Krueger, 1977)

Televanilla's technical set-up, particularly in the third section, was indeed of a sensing and a display component, and a very basic analogue computer control system. It could accept input about the participant through a camera interface, and it produced a visual output corresponding to the dancer's behaviour.

The main accomplishment of Televanilla was the combination of two separate concepts that were evident in the late 1960s New York art scene in a single performance. Firstly, the notions of audience interaction and participation that were explored in various performances and early video artworks, as evidenced in the discussions on the 1960s imageprocessing art scene, Klüver's $9 E$ venings, and Wise's $T V$ as a $C$ reative $M$ edium. Secondly, the technical potential that image processing devices provided for creating distinct techno-aesthetics for the visual representation of reality that the underground television art scene developed.

The amalgamation of these two concepts introduced a responsive technical environment that enabled not only the performer but also the audience after the show to engage with their virtual representation in the space of an electronic medium through a humanmachine interface.

\section{CRITICAL RECEPTION}

Despite the technical and conceptual novelties in this interdisciplinary work, the performance was not particularly successful. It did not make any significant impact on the emerging New York art scene that attempted to amalgamate media technology and performative art at the end of the 1960s and hardly left any noticeable trace in the annals of dance, performance or media in the years and decades after that.

Although it did not get off to a particularly bad start: the piece was produced in collaboration with Paul Libin, an influential impresario in the Broadway and Off-Broadway theatre art scene in post-war New York. ${ }^{5}$ Within the next two months, Televanilla received four reviews from renowned critics in reputable publications: Jacqueline Maskey's brief review in the next day's The $N$ ew York $T$ imes (Maskey, 1968), Deborah Jowitt's May $2^{\text {nd }}$ review in The Village Voice (Jowitt, 1968), Jack Anderson's brief article in the June $8^{\text {th }}$ Dance Magazine 
(Anderson, 1968), and Marcia B. Siegel's review in the New York Magazine (Siegel, 1968). The first three reviews were not exactly enthusiastic, and the reviewers were apparently a bit at a loss with what they had seen.

Marcia B. Siegel's article "Televanilla: $T$ heatre in Two Flavors" in the New York Magazine on $10^{\text {th }}$ of June 1968 was the most thorough analysis of the performance (Siegel, 1968). She not only described the evening by elaborating on some more or less favourably perceived elements or components, but also contextualised the whole performance in the larger framework of contemporary dance and theatre at the time.

Her review focused on two key elements presented in the event, each corresponding to one of the critical "currents of change that are influencing dance theatre": Firstly, she related Televanilla's deployment of television technology on stage to the late 1960s intermedia performances and happenings. Siegel makes a fine distinction between real space and its virtual representation in technological media in arguing that the experience of the extended self through technical devices in intermedia performances entailed the "projection of self into another sphere of time and space". In further pursuing this line of argument, Siegel implies that a mediated representation would be able to create a virtual reality, which potentially superseded the importance of the actual reality on stage: "If this projection of self begins to seem real, then the actual reality, the actual moment, has been obliterated".

Siegel concludes that Televanilla has achieved precisely this transgression between the real and the virtual: "In Televanilla the live dancer became less real, and less interesting, than the multiple versions of her that were being projected onto the screens". This sequence of three brief sentences, part of a not too lengthy elaboration on the subject of media performances in a rather general tone, constitute one of the earliest, albeit quite cautious, characterizations of a conceptual framework for virtual reality. It carries significant affinities to Myron Krueger's definition of 'artificial reality' systems.

However, she notably did not connect her observation related to the creation of 'virtual reality' through technological media with the second distinct element that she identified as significant in the event. This part of her review was concerned with the various examples of participatory approaches that Televanilla presented. In referencing again intermedia performances and its many attempts to incorporate audience participation in the theatrical event, Siegel critically examined the accomplishments of these endeavours. She remarked that the objective was to overcome "the type of ritual in which the audience is conditioned to sit in decorous neutrality and receive signals from the stage". However, she emphasised that the audience in intermedia performances remain essentially passive, too. Siegel concluded: "Intermedia appeals to the same instinct for blocking out the world that it is supposed to counteract".

She further noted that "Intermedia is approaching the limits of sensory excitation", and would face the danger "to nullify itself by pushing over the threshold of pain, oblivion or total chaos". Siegel suggested what she called the 'humanistic theatre' as an approach to counter the tendency towards increasingly dehumanising spectacles. Siegel defined humanistic theatre as an outgrowth of early happenings, concerned with "the environmental and interpersonal elements of the world". It would provide a broad range of opportunities to develop performances "based on loosely structured dance movement [or] improvisational group activity", and that could include intermedia approaches and devices.

This remark conceptually opens the stage to the audience and invites this audience to assume a significant role within the mediated performance through modes of interaction with media technology. Siegel specifically emphasised that Televanilla applied this concept when it broke down the traditional separation between stage and audience. During the two intermissions and particularly after the third section when the audience was invited to experiment with the Videosketch device, the audience 'literally' became performers, as Siegel pointed out. Apparently, this novel approach to invite the audience to the stage for interaction with the technology was quite successful, as she further observed that the participants, after creating "designs on the radar screen [...] went home reluctantly, as if they were leaving a party".

Siegel emphasised that two distinct events were taking place simultaneously in Televanilla: The creation of a virtual representation of the dancer in a mediated environment, and the introduction of modes of interaction with media technology for the broad 'laymen' audience. These two concepts also designate the key elements that constitute computer-based interactive art environments, although Siegel's immensely thoughtful review fell short in explicitly making this connection for the purpose of defining an entirely novel art form that combines two existing approaches for the creation of a new artistic concept.

\section{REPERCUSSIONS}

Despite this quite encouraging final review, the production managed to slip out of the records related to the history of media technology and performative art so completely that it is hardly possible to find any evidence of its existence in the critical literature today. During the following couple of years, Televanilla was referenced only briefly and factually 
on a few occasions mostly in the biographical notes of two of the participating artists (Wise, 1969) (Connor, 1970) (Siegel, 1970) (Yalkut, 1970) In 1991/92, Siegel referenced Televanilla, and also provided some details about his image processing devices of that time, in interviews conducted in preparation for the ARS Electronica show Pioneers of Electronic Art. ${ }^{6}$

In 1972, Marcia Siegel republished her New York Magazine article in At the Vanishing Point: A C ritic Looks at Dance (Siegel, 1972). In the years leading to 1984, Jud Yalkut was working on a larger publication titled Electronic $Z$ en: $T$ he $A$ Iternative Video Generation. Yalkut included an introduction to Televanilla, and an interview with Buirge and Boutourline, which he recorded in 1968. The book, however, remained unpublished (Yalkut, 1984b).

Apart from these, very few archives and encyclopaedias list Televanilla. The Oxford Dictionary of Dance references the performance under the entry for Susan Buirge. Televanilla is also mentioned briefly and factually in the archives of the Fondation Royaumont as part of the Buirge collection, and the online archive of the Experimental Television Center. Finally, Susan Buirge published her autobiography Une Vie Dans L'Espace De La Danse (Buirge, 2012), in which she presented a brief account of the performance in the wider context of her career as dancer and choreographer.

The interesting, albeit conceptually and artistically tentative effort presented in Televanilla failed to attract further significant attention. None of the otherwise, in their particular focus, comprehensive publications that are concerned with works at the intersection of art, performance and media technology mentions Serge Boutourline, or Susan Buirge, or Televanilla, or Videosketch.

\section{TOO LITTLE, TOO EARLY}

One contributing factor was that within the span of a few years, none of the participating artists attempted to pursue the concept that Televanilla introduced any further. In fact, all five artists entirely ceased their involvement in any artistic practice of this kind.

However, the principle reason why Televanilla became one of the many soon-to-be-forgotten artistic events in the late 1960s New York art scene was that it firmly situated itself between the then existing discourses for performative art. The highly experimental nature of the performance resulted in a hesitant overall outcome and experience for the audience, as all reviewers remarked. It was less performance and more a proving ground for some new media technology in a stage environment, and for some rather unresolved conceptual approaches to working artistically with these media.
As an avant-garde dance performance, the artistic limitations in the choreographic concept were too obvious, and the dance itself too compromised by the efforts to incorporate media technology on the stage, as Buirge reaffirmed self-critically almost 50 years after the event (Buirge, 2016).

As an intermedia event, there was just not enough 'sound and fury' on stage. There were only seven small monitors at the fringe of the stage and an improvised screen upstage in one of the three pieces. The audience only experienced black and white imagery with rather unfamiliar visual aesthetics, and spectators needed to put chromatic gels in front of their eyes for colour vision. Furthermore, the dance relied primarily on delicate and elusive movements accompanied by sounds of nature and minimalist music. Parts of the audience must have compared this toned-down event with performances that were "stimulating, often violently, as many sensory organs as possible", which Marcia Siegel attributed to the many intermedia performances of that time (Siegel, 1968). In the words of Deborah Jowitt, it was "a too-short-for-themoney event [that] had damned well better be something cosmic" (Jowitt, 1968).

Those who interpreted Boutourline's announcement of "experimental interaction between audience, performer and simultaneous T.V. system" (Boutourline, 1968) as 'audience participation' must have been surprised that the evening entirely neglected the common approaches to this concept for intermedia performances. None of Televanilla's three dance sections required nor expected any active involvement of the audience in what happened on stage. Instead, opportunities for audience participation were offered only during the two intermissions, and after the last section, although the artists carefully orchestrated these moments, as Buirge remembers (Buirge, 2016).

Breaking down the traditional audience-stage distinction finally introduced a very different kind of audience participation, for which the audience was only little prepared. It corresponded far more to the concept of human-machine interaction through a human-computer interface than to concepts of audience participation that arose from happenings and intermedia performances.

Moreover, the accompanying discourse on this particular issue related to artistic practice with media technology was barely noticeable in early 1968 . Although concepts of interaction between humans and electronic devices were subject to intensive research, they were mostly confined to the research labs of large technology companies or academic institutions.

The emerging tech-art scene experimented on many levels with new approaches to establish communication and interaction with technical 
devices, but few of these works transcended the idea of such interactivity beyond the limits of the existing human-machine interface. As Söke Dinkla remarked in 1994 in her essay The History of the Interface in Interactive Art, "at that time no one in the 'art world' thought of creating a more complex computer-controlled dialogue and focusing the interaction itself" (Dinkla, 1994).

\section{CONCLUSION}

In early 1968, Televanilla presented key elements required for a dialogical system with an electronic device that incorporated the notion of two-way interaction: a camera-based, motion-controlled human-machine interface that allowed for real-time interactivity between a non-expert participant and his mediated representation. The overall context of a dance performance in which the artists presented this concept reaffirms the significant links that connect 1960s performance art with the technologybased interactive art that evolved in the late 1980s. Chris Salter has rightfully emphasised these links, and also highlighted that these links were not appropriately recognised in the critical discourse on interactive art (Salter, 2010).

Televanilla made a tentative approach to expanding the concept of interactivity beyond the boundaries of the stage. The artists' decision to provide the audience with the opportunity to experiment with the interactive potential of an electronic device after the performance situated the concept of participation and interaction outside the immediate confines of performance art. It created an alternative, liminal space for such artistic activities that located between the traditional concepts of performance art and fine art practice.

However, Televanilla did not push the idea of technology-based interactivity through an open human-machine interface decisively towards a new artistic practice. Neither the artists involved in the performance nor the critical discourse in late 1968 were prepared to recognise this highly interdisciplinary liminal space as more than a compromise that imposed limitations on existing artistic disciplines, as opposed to embracing the opportunity to define and evolve a novel conceptual framework for artistic practices.

Nonetheless, the theoretical foundations for this discourse were laid in the 1960s with the vast diversity of artistic experiments with media technology, concepts of audience participation, and interfaces for human-machine interaction.

The ambiguous critical review of Televanilla presents a remarkable example of the significant issues that this discourse at the end of the 1960s had with an artistic practice based on protopostmodernist cybernetic principles that challenged the existing modernist concepts for art and artwork and the roles of artist and audience within this framework.

\section{REFERENCES}

Anderson, J. (1968) Televanilla: Martinique Theatre: April 22, 1968. Dance Magazine (June), 42(6), 87-88.

Boutourline, S. (1968) Televanilla Press Release. The Circle in the Square Papers, *T-Mss 2005005. Billy Rose Theatre Division, The New York Public Library for the Performing Arts, Archives \& Manuscripts.

Buirge, S. (2012) Une Vie dans I'Espace de I a Danse. I'Isle-sur-la-Sorgue: Le Bois d'Orion.

Buirge, S. (2016) Correspondance with Author (2013-2016)

Chamberlain, W. (2014) Correspondance $w$ ith Author

Comer, S. (2012) Propaganda for the Politics of Joy and Disorder. Vertigo, Winter 2012(31).

Connor, R. (1970) Vison\&Television. Waltham, Mass.: Rose Art Museum, Brandeis University.

Dinkla, S. (1994) The History of the Interface in Interactive Art., ISEA I nternational $S$ ociety $f$ or Electronic $\mathrm{Ar}$ t. Helsinki, Finland: ISEA International Society for Electronic Art.

EAl Archive (2014) Variations $V$ : $M$ erce Cunningham. Electronic Arts Intermix Archives Online. Retrieved 14.08.2014.

Jowitt, D. (1968) Message from Susan. The Village Voice, (May 2), p. 29.

Kozol, J. (1988) Rachel and her Children: Homeless Families in America. New York: Crown Publishers I Random House Inc.

Krueger, M. W. (1977) Responsive Environments. Proceedings of the J une 13-16, 1977, National Computer Conference. Dallas, Texas, ACM.

Krueger, M. W. (1983) Artificial R eality. Reading: Addison-Wesley.

Kwastek, K. (2013) Aesthetics of I nteraction i $n$ Digital Art. Cambridge, Mass.: MIT Press.

Mann, T. (2005) The Circle in the Square Papers. Billy $R$ ose $T$ heatre $D$ ivision. (26.08.2016. New York: The Circle in the Square Papers, ${ }^{*} \mathrm{~T}$-Mss 2005-005. Billy Rose Theatre Division, The New York Public Library for the Performing Arts, Archives \& Manuscripts.

Margolies, J. S. (1969) TV - The Next Medium. Art in America, 57(5 (September - October), pp. 4855. 
Maskey, J. (1968) 'Televanilla' Dance Offers Free Daisies, The N ew York Times (April 23). New York 1968

Salter, C. (2010) Entangled: T echnology an d the Transformation of $P$ erformance. Cambridge, Mass.: MIT Press.

Siegel, E. (1970) Radical Software, 1(1), 19.

Siegel, E. (1991) Interview by Katharina Gsöllpointner: December 1991. Vasulka Archive. Retrieved 12.03.2014, http://www.vasulka.org/archive/Artists6/Siegel,Er ic/Interview.pdf.

Siegel, E. (1992a) Interview by Woody Vasulka: January 1992 (Draft). Vasulka Archive. Retrieved 12.03.2014,

http://www.vasulka.org/archive/RightsIntrvwInstit MediaPolicies/IntrvwlnstitKaldron/74/Siegel.pdf.

Siegel, E. (1992b) Interview b y W oody $V$ asulka: January 19 92. Vasulka Archive. Retrieved 12.03.2014,

http://www.vasulka.org/archive/RightsIntrvwlnstit MediaPolicies/IntrvwlnstitKaldron/75/Siegel,Eric. pdf.

Siegel, M. B. (1968) Televanilla: Theatre in Two Flavors. New York Magazine (June 10), 1(10), 5758.

Siegel, M. B. (1972) At the Vanishing Point: A Critic Looks at Dance. New York, US.: Saturday Review Press, E. P. Dutton.

Spielmann, Y. (2014) Analog to Digital: Artists Using Technology, in High, K., Miller-Hocking, S. \& Jimenez, M. (eds), The $E$ mergence of $V$ ideo Processing Tools: Television Becoming Unglued. Chicago, USA: Intellect, The University of Chicago Press, 499-527.

Watson, S. (2011) Tube Boobs. Art Forum (Summer 2011), p. 121.

Wise, H. (1969) TV as a Creative Medium: Exhibition Brochure, Howard Wise Gallery New York. New York: Electronic Arts Intermix Archives Online. Retrieved 22.08.2014, http://www.eai.org/user_files/supporting_docume nts/tvasacreativemedium_exhibitionbrochure.pdf

Yalkut, J. (1970) Interview with Eric Siegel. Radical Software, 1(2), 21.

Yalkut, J. (1984a) Eric Siegel: The Electronic Video Synthesizer, in Yalkut, J. (ed), Electronic Z en: The A Iternative $V$ ideo Generation, Vasulka Archive, pp. 206-212. Retrieved 12.03.2014, http://www.vasulka.org/archive/Artists10/Yalkut,J ud/ElectronicZen.pdf.

Yalkut, J. (1984b) Televanilla: Susan Buirge and Serge Boutourline: The Human Use of Television. Interview conducted in 1968, in Yalkut, J. (ed),
Electronic Zen: The Alternative Video Generation, Vasulka Archive, pp. 89-102. Retrieved 12.03.2014,

http://www.vasulka.org/archive/Artists10/Yalkut,J ud/ElectronicZen.pdf.

\section{ENDNOTES}

${ }^{1}$ All information related to the description of the performance, if not otherwise indicated, were provided by Susan Buirge, through personal communication between 2013 and 2016, email correspondence between Buirge and the author (Buirge, 2016), or from Buirge's autobiography (Buirge, 2012).

2 John Margolies credited Peter Sorensen as the artist who exhibited Lumokinetic Paint Set in 1968, which deployed a technological device capable of creating abstract patterns and distortions of a transmitted television image, however without providing further details (Margolies, 1969, p54). Deborah Jowitt indicated in her The Village Voice review on May 2, 1968 that Sorensen contributed the 'effect $g$ enerator' for the piece (Jowitt 1968). Siegel highlighted in several interviews that he developed the tool himself.

${ }^{3}$ As Buirge recalls, the original concept specified a real-time projection of the dancer's legs with a video projector. However, limitation of the projector technology in 1968, particularly the low luminosity of the projected video images would have significantly compromised the visual quality of the video. Therefore, the artists resorted to film footage, which was conceived and recorded by Wynn Chamberlain (Buirge, 2016).

${ }^{4}$ Spielmann discusses the conceptual and technical overlap between analogue and digital computer in detail in her 2014 essay Analogue to Digital: Artists Using Technology. She concludes that "the borders between analogue and digital computers are permeable", that "video processing means a kind of computing", and that these tools "can be discussed under the rubric of machines with programmable functions" (Spielmann, 2014, pp507ff).

${ }^{5}$ For more than 25 years, Libin was Managing Director and Producing Director for Circle I $n$ the Square, a not-for-profit off-Broadway theatre company. In 1958, he converted the ballroom of the Martinique Hotel near Broadway into a 225-seating theatre and presented Arthur Miller's The Crucible. Libin continued to use the Martinique Theatre for his productions, as well as for Circle in the S quare shows. These included performances of Robert Whitman and Carolee Schneemann in 1966, Viet Rock (the precursor of Hair for which Libin later served as General Manager) in 1966/67, and The Gorilla Queen, a critical work of the Theatre of the Ridiculous in 1967 (Mann, 2005). 
6 The parts of the interviews that related to Televanilla were omitted in the final publication (Siegel, 1991), (Siegel, 1992a), (Siegel, 1992b).

7 Buirge identifies her 1980 dance performance Sifter, which was remounted in 2014 in Singapore at the Esplanade Theatre Singapore in collaboration with LASALLE College of the Arts, as example for this approach.

${ }^{8}$ Brand $X$ premiered in 1970 , disappeared shortly after that for 38 years under circumstances that Chamberlain described as a conspiracy by the Nixon administration (Comer, 2012). It was re-opened with much critical acclaim in 2011 at the New Museum in New York, followed by numerous screenings at international venues, including the Tate Gallery London and the Berlin Film in 2012.
9 Jonathan Kozol eternalized this chapter in the history of the hotel in his 1988 novel Rachel and her Children: $H$ omeless $F$ amilies i $n$ A merica (Kozol, 1988)

\section{ACKNOWLEDGEMENTS}

This research received support from the Research Committee of LASALLE College of the Arts, Singapore. 